\title{
Comment on "Shifts and twists in the relative productivity of skilled labor"
}

\author{
Leo Kaas \\ University of Konstanz, Box DI45, 78457 Konstanz, Germany
}

The paper by Dupuy and Marey analyzes changes of the elasticity of substitution between skilled and unskilled labor. In the empirical section they provide evidence that, in the United States between 1963 and 2002, this elasticity has first decreased and then increased. On the other hand, it is well known that this period has been characterized by a substantial increase in the relative supply of skilled labor. The question that arises is: what explains the non-monotone change in the elasticity of substitution? Although the theoretical part of the paper lays out a neat microeconomic foundation of the CES production function (which is based on a model of Rosen (1978)), it cannot really address this question. The elasticity of substitution between skilled and unskilled labor is an exogenously given parameter in their model.

In the following, I develop a simply model that can explain the observed non-monotone evolution of the elasticity of substitution as an endogenous response of a two-sector economy to an increase in the relative supply of skilled labor. The economy is very stylized, functional forms are simple, and there are no efficiency parameters of skilled and unskilled labor. The purpose is to illustrate the key point with as little formalism as possible.

Aggregate output $Y$ is produced from two intermediate inputs $Y_{1}$ and $Y_{2}$ according to Cobb-Douglas technology $Y=Y_{1}^{\alpha} Y_{2}^{1-\alpha}$. Both intermediate-good sectors produce their output from skilled and unskilled labor. In sector 1, the two labor types are perfect complements, output is $Y_{1}=\min \left(S_{1}, U_{1}\right)$. In sector 2 , there is some substitutability and the production function is Cobb-Douglas, $Y_{2}=S_{2}^{\beta} U_{2}^{1-\beta}$. The price of final output is normalized to unity, prices of intermediate goods are $p_{1}$ and $p_{2}$, and prices for skilled and unskilled labor are $w_{\mathrm{s}}$ and $w_{\mathrm{u}}$. Labor supply is exogenous, and the two labor markets clear if $S=S_{1}+S_{2}$ and $U=U_{1}+U_{2}$. All markets are perfectly competitive.

\footnotetext{
E-mail address: leo.kaas@uni-konstanz.de
} 
In the competitive equilibrium, the relative price of the two intermediate goods is

$$
\frac{p_{1}}{p_{2}}=\frac{\alpha}{1-\alpha} \frac{Y_{2}}{Y_{1}} .
$$

Wages for skilled and unskilled labor are equal to their marginal products in sector 2:

$$
w_{\mathrm{s}}=\beta\left(\frac{U_{2}}{S_{2}}\right)^{1-\beta} p_{2}, \quad w_{\mathrm{u}}=(1-\beta)\left(\frac{S_{2}}{U_{2}}\right)^{\beta} p_{2} .
$$

Firms in sector 1 employ skilled and unskilled labor equally, $Y_{1}=S_{1}=U_{1}$, and their zeroprofit condition is $p_{1}=w_{\mathrm{s}}+w_{\mathrm{u}}$. Using this and (2) yields another equation for the relative price of intermediate goods:

$$
\frac{p_{1}}{p_{2}}=\beta\left(\frac{S_{2}}{U_{2}}\right)^{\beta-1}+(1-\beta)\left(\frac{S_{2}}{U_{2}}\right)^{\beta} .
$$

Let $v=U_{1} / U$ be the share of unskilled labor in sector 1 , and let $\mu_{i}=S_{i} / U_{i}$ be the skill intensity in sector $i=1,2$. Clearly, $\mu_{1}=1$ and $Y_{2} / Y_{1}=\mu_{2}^{\beta}(1-v) / v$. Substitute the last equation into (1) and equate it to Eq. (3) to obtain

$$
\frac{\beta}{\mu_{2}}+1-\beta=\frac{\alpha}{1-\alpha} \frac{1-v}{v} \text {. }
$$

On the other hand, $S=S_{1}+S_{2}$ implies

$$
\mu=v+\mu_{2}(1-v),
$$

where $\mu=S / U$ is the exogenously given relative supply of skilled labor. Eqs. (4) and (5) can be solved for a unique pair $\left(\mu_{2}, v\right)$ for any choice of $\mu$. It is straightforward to show graphically that both $\mu_{2}$ and $v$ are increasing in $\mu$. Importantly, the relation between $\mu_{2}=S_{2} / U_{2}$ and $\mu=S / U$ is not $\log$-linear. Instead, $\mathrm{d}\left(\ln \left(\mu_{2}\right)\right) / \mathrm{d}(\ln (\mu))$ is increasing at $\mu<1$, but decreasing at $\mu>1$. It is largest at $\mu=1$. This finding has an important implication for the skill premium which is, from (2),

$$
\frac{w_{\mathrm{s}}}{w_{\mathrm{u}}}=\frac{\beta}{1-\beta} \frac{1}{\mu_{2}(\mu)} .
$$

Clearly, a $1 \%$ increase of the relative input of skilled labor in sector 2 triggers a one percent decrease of the skill premium. However, the response of the skill premium to changes in the relative supply of skilled labor is again not log-linear. Instead, it is largest at $\mu=1$, but attains smaller values both at $\mu<1$ and at $\mu>1$. Consequently, the measured elasticity of substitution

$$
\sigma \equiv-\frac{\mathrm{d} \ln (\mu)}{\mathrm{d} \ln \left(w_{\mathrm{s}} / w_{\mathrm{u}}\right)}=\frac{\mathrm{d} \ln (\mu)}{\mathrm{d} \ln \left(\mu_{2}\right)}
$$

is smallest at $S=U$, but larger when $S<U$ or when $S>U$. This pattern is illustrated in Fig. 1, which illustrates the response of the aggregate elasticity of substitution when the relative supply of skilled labor $S / U$ varies between 0.5 and 2 and when $\alpha=\beta=0.5$. Thus, this simple model explains why a steady increase of the relative supply of skilled labor can 


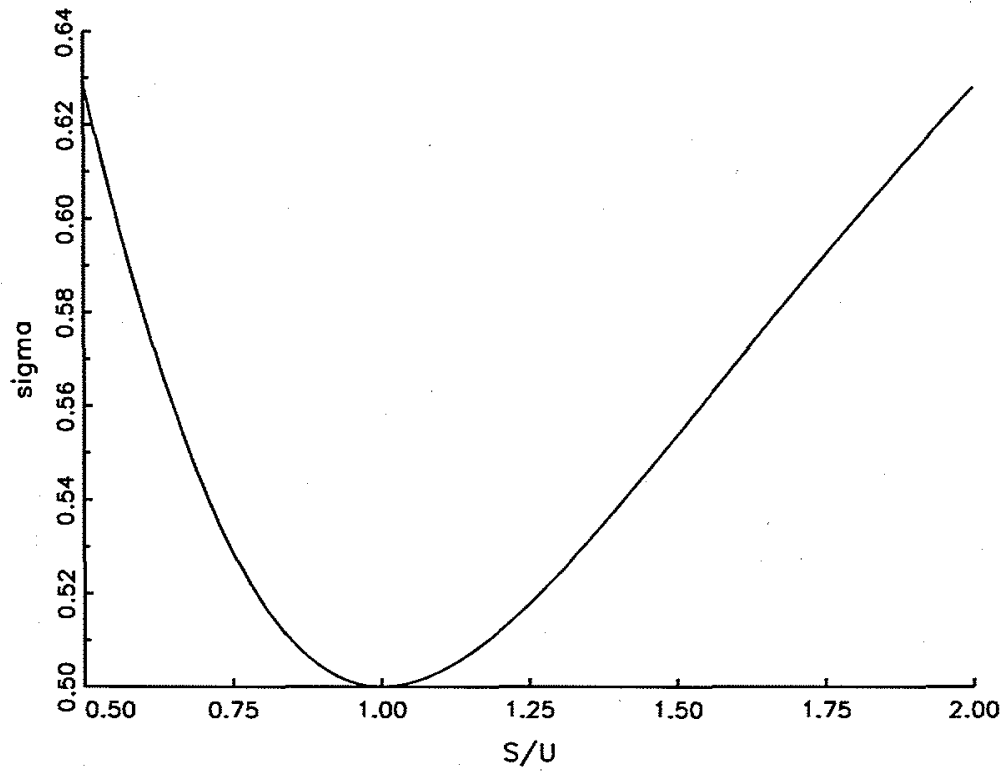

Fig. 1. Response of the elasticity of substitution between skilled and unskilled labor when the relative supply of skilled labor varies between 0.5 and 2.0 and $\alpha=\beta=0.5$.

trigger a non-monotone response of the measured elasticity of substitution, in line with the empirical finding of Dupuy and Marey.

What explains this result? At $S=U$, intermediate good 1 can be produced at relatively low cost since its skill requirement $\left(S_{1}=U_{1}\right)$ matches the relative skill supply. But when $S>U$ and when $S<U$, the production of good 1 becomes less attractive than the production of good 2 which allows for more substitutability. In both cases, intermediate good 1 becomes more expensive relative to intermediate good 2, so $Y_{1} / Y_{2}$ falls. Consequently, the aggregate elasticity of substitution attains a minimum at $S=U$. 